\title{
- RTI Photoluminescent Nanofibers for Solid-State Lighting Applications
}

L. Davis, L. Han, P. Hoertz, K. Guzan, K. Mills, H.Walls, T. Walker, and D. Magnus-Aryitey RTI International, Research Triangle Park, NC, USA
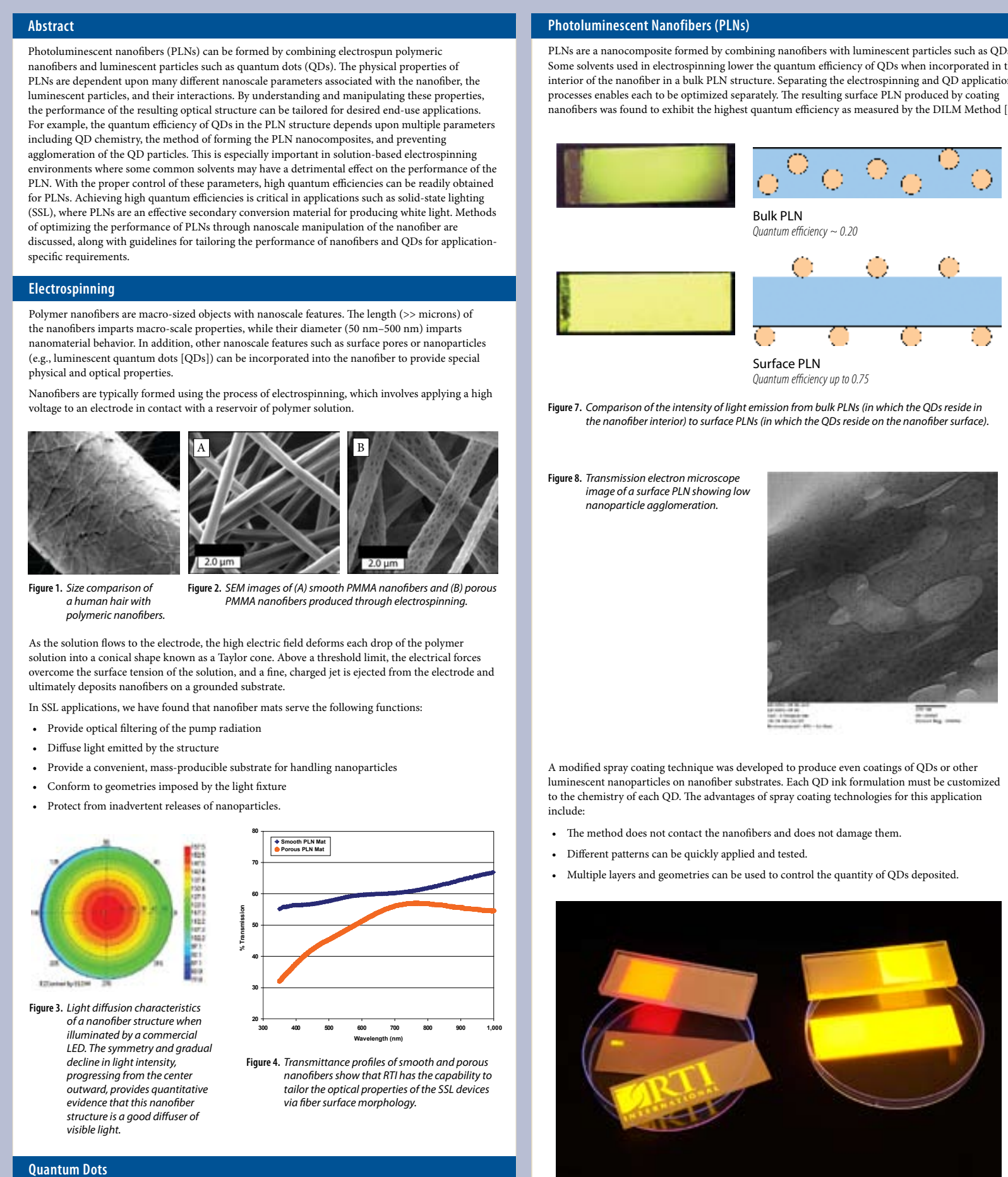

- Difierent patterns can be quickly applied and tested.
- Multiple layers and geometries can be sed to control the quantity of QDs deposited.
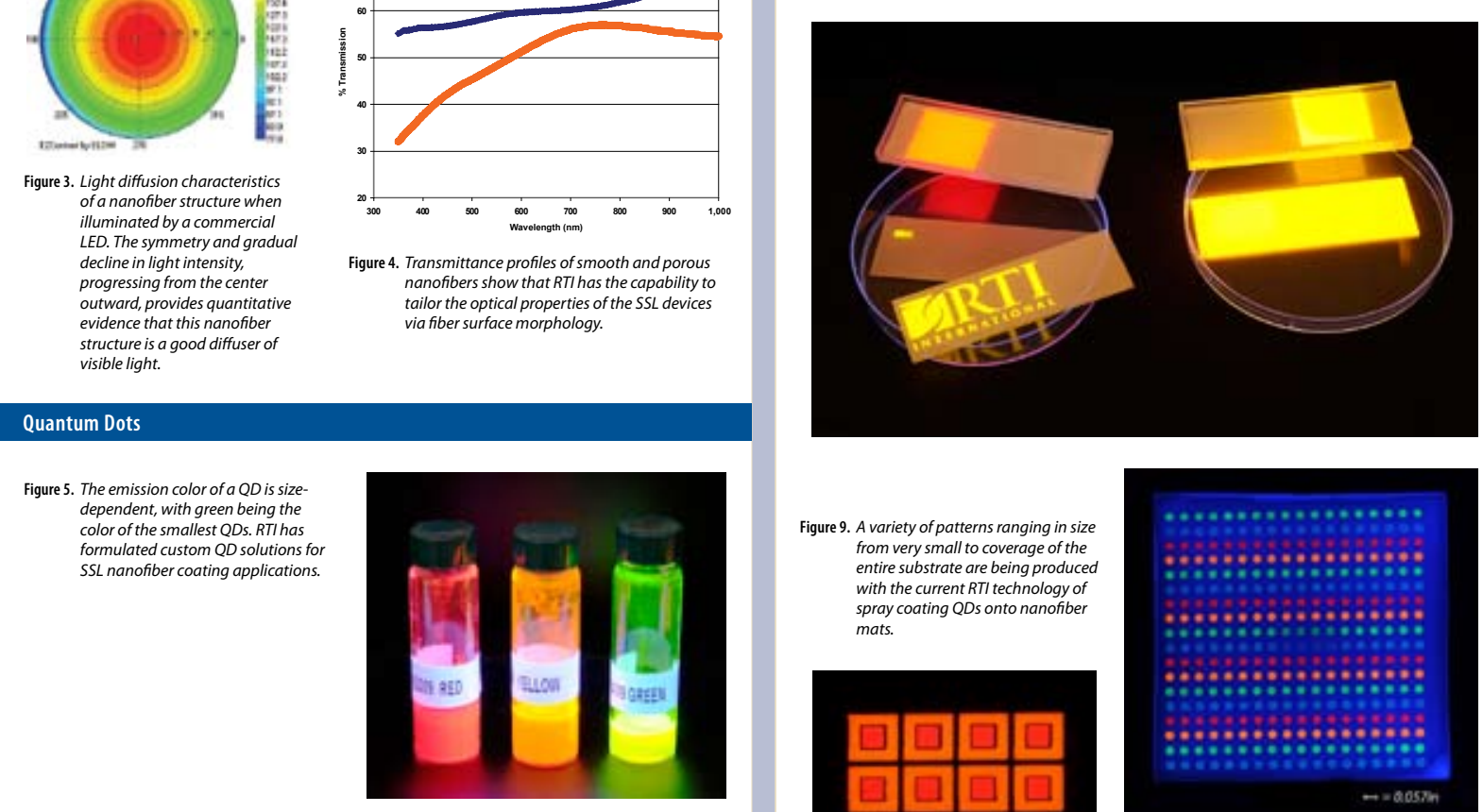

The quantum dots used in the spray coating solution have the following properties:

- The $\mathrm{QD}$ consists of s semiconducting CdSe core that absorbs short wavelengths and emits longer

A ZnS shell surrounds the core and provides environmental stabil

A long-chain amine coordination sphere is attached to the ZnS shell to provide compatibility

QDs can be coated on the surface of the nanofibers singn various methods such as spray coating
and dip coating. For SSL applications, we have determined that a modified spray coating method
produces the best properties in the PIN.
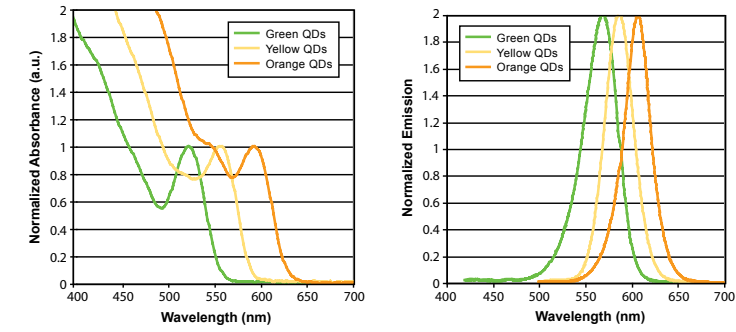

Figure 6 . Normacina
projec.

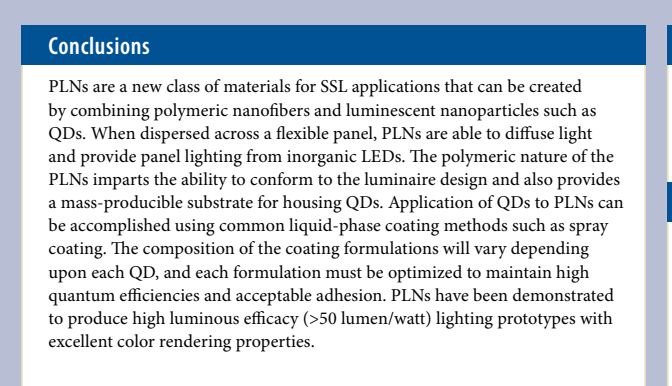

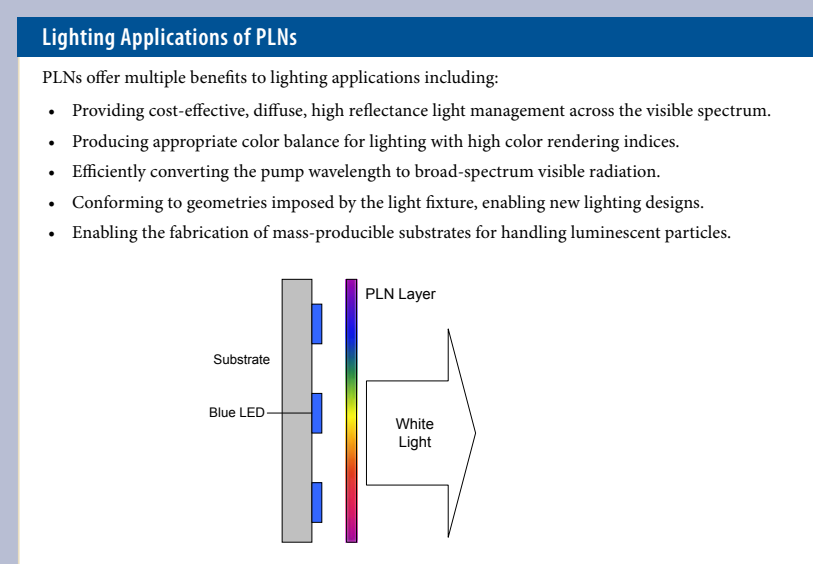

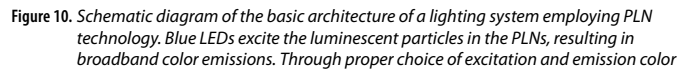

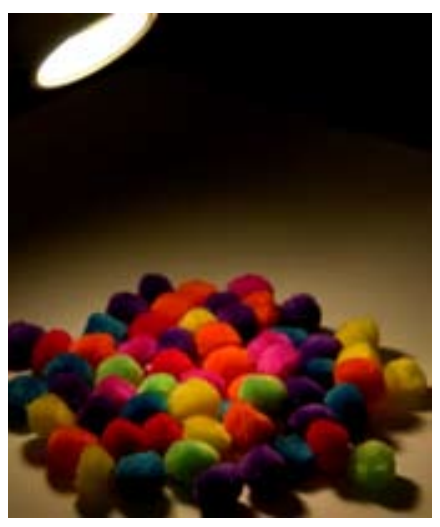

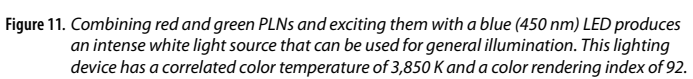
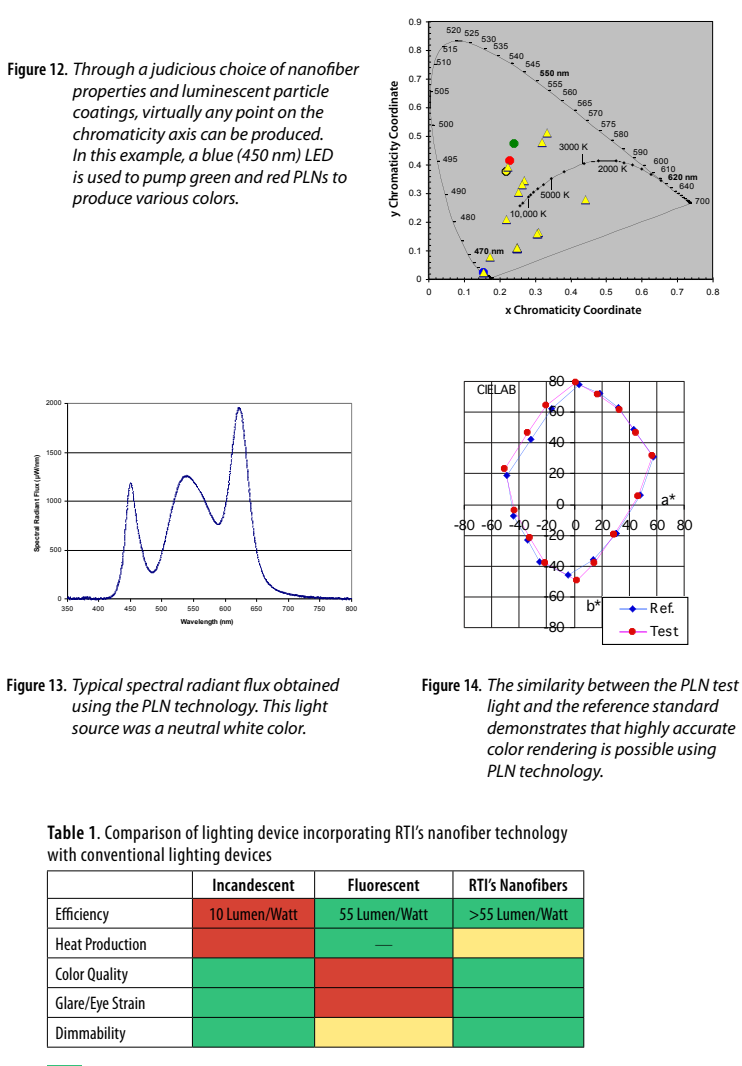

Exelent performance
Moderate perforance
Lower than desired perform
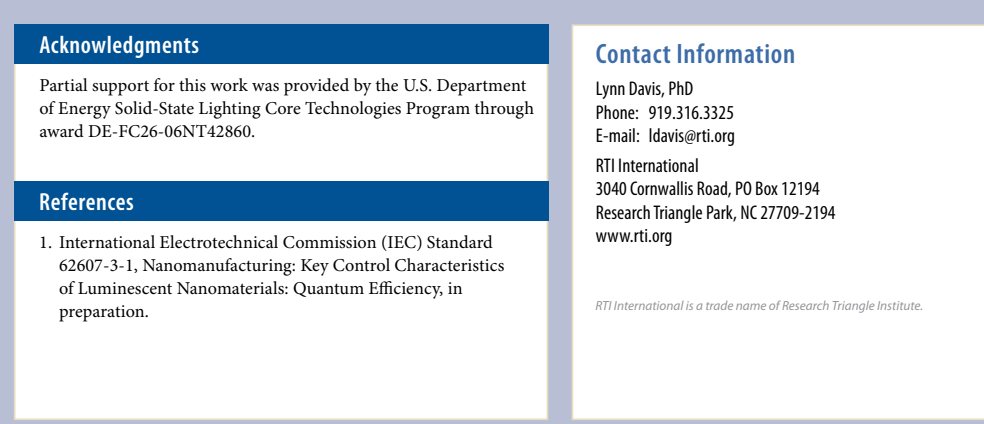